Universidade de Brasília

Faculdade de Economia, Administração, Contabilidade e Ciências da Informação e Documentação (FACE)

Walcymar Pereira Santiago

Giulliano Rezende Silva

CAUSAS DO SOFRIMENTO NO TRABALHO DOS TÉCNICOS DE LABORATÓRIO DA FACULDADE DE MEDICINA DA UNIVERSIDADE DE BRASÍLIA 
Walcymar Pereira Santiago

Giulliano Rezende Silva

\section{CAUSAS DO SOFRIMENTO NO TRABALHO DOS TÉCNICOS DE LABORATÓRIO DA FACULDADE DE MEDICINA DA UNIVERSIDADE DE BRASÍLIA}

Monografia apresentada à Faculdade de Economia, Administração, Contabilidade e Ciência da Informação e Documentação (Face), da Universidade de Brasília, como requisito à obtenção do grau de Especialista em Gestão Universitária.

Orientador: Prof. Dr. Marcus Vinícius Soares Siqueira. 
A Walcy e Martha.

A Maria Aparecida. 


\section{AGRADECIMENTOS}

Às nossas famílias pelo engajamento nessa nossa jornada.

A Susana pela ajuda, paciência, dedicação, confiança e o estímulo demonstrado na minha capacidade de enfrentar um novo desafio.

Aos nossos colegas de turma, que sempre nos apoiaram e às amizades que se perpetuarão na nossa lembrança.

Ao professor Marcus Vinicius Soares Siqueira pela competência e demonstração de apreço.

A shigueru pela solidariedade, amizade, companheirismo e compreensão pela minha ausência temporária.

Ao professor Vicente e ao meu colega Carlos pela demonstração de companheirismo. 


\section{RESUMO}

A pesquisa em questão pretende analisar as principais causas de sofrimento no trabalho, vivenciados por técnicos de laboratório no âmbito de uma Instituição Pública de Ensino Superior. Os objetivos específicos residem na análise das relações de trabalho envolvendo docentes e servidores técnicos de laboratório, além de verificar as condições de trabalho e propor melhorias. Obviamente o trabalho hoje, não se constitui só de fonte de subsistência, conquistas, reconhecimento pessoal e participação social, mas na maioria das vezes, de fonte de opressão, exploração, discriminação e exclusão dos indivíduos. Com essa visão o estudo abordou As Relações de Trabalho nas Organizações Contemporâneas e as Considerações sobre a Psicodinâmica do Trabalho.

Participaram de entrevistas semi-estruturadas 15 servidores, respondendo a questões relativas às suas condições de trabalho, relacionamentos socioprofissionais, organização do trabalho, percepção de sofrimento dentre outras. Verificou-se na análise do discurso a subjetivação coletiva do sofrimento, decorrido principalmente das condições precárias a que são submetidos e concluiu-se que a organização apela para o ego imaginário, reforçando a vinculação desses trabalhadores.

Palavras-chave: sofrimento, condições de trabalho, subjetivação coletiva. 
LISTA DE QUADROS

Quadro 1- Perfil dos entrevistados.

Quadro 2- Tempo de serviço na Instituição... 


\section{SUMÁRIO}

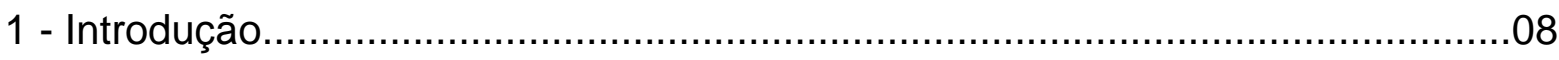

2 - Fundamentação teórica.............................................................................12

2.1 - As Relações de Trabalho nas Organizações Contemporâneas........................12

2.2-Considerações sobre a Psicodinâmica do Trabalho.........................................17

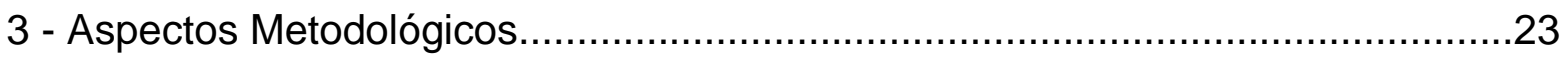

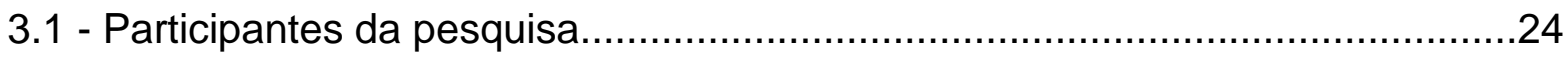

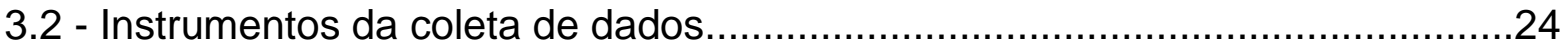

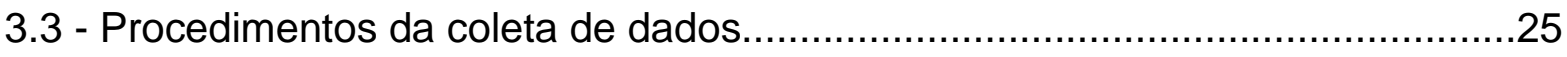

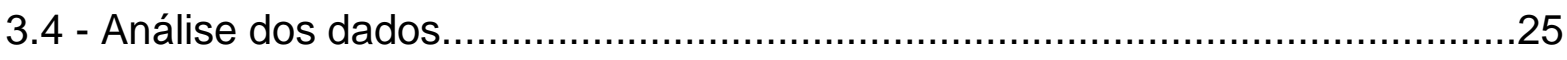

4 - Apresentação e discussão dos resultados...................................................27

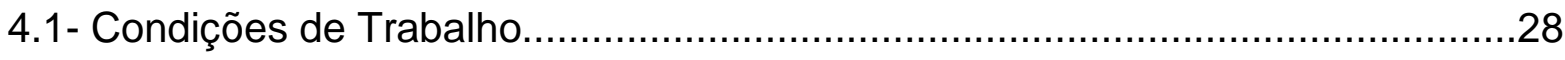

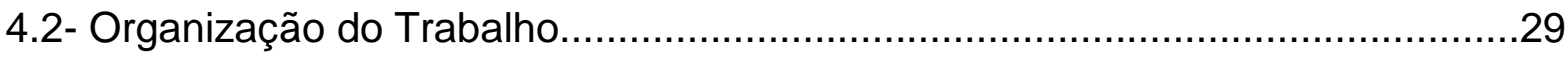

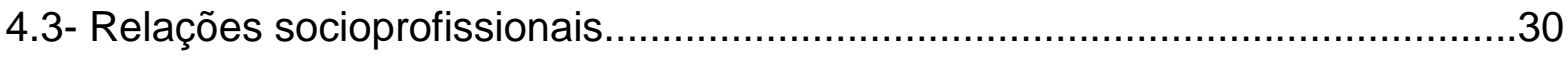

4.4- Danos físicos e psíquicos.........................................................................

4.5- Percepção de Sofrimento no Trabalho..........................................................32

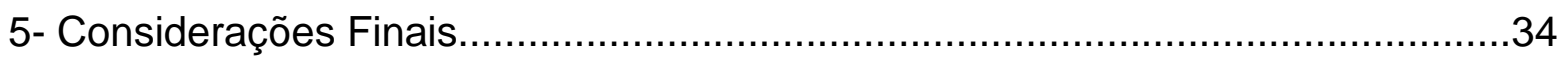

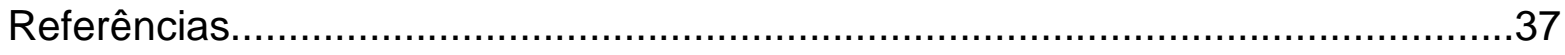




\section{1- Introdução}

Com as mudanças decorrentes dos processos de globalização e avanços tecnológicos cada vez mais acelerados, fatores esses que condicionam as organizações e os profissionais a uma competitividade cada vez mais "injusta" e acirrada, muitas vezes causando o adoecimento físico e psíquico dos trabalhadores, cientistas de várias áreas perceberam a necessidade de desenvolver pesquisas e estudos que explicassem esse fenômeno.

Inicialmente o trabalho era estudado considerando as condições de sua execução, ambiente, exposição e movimentos. As primeiras pesquisas tinham como objetivo analisar as condições a que eram submetidos os trabalhadores e eram focadas apenas nas questões relativas à exposição dos indivíduos a ambientes insalubres, perigosos e a atividades que redundassem em adoecimento do seu corpo físico.

É possível perceber que o trabalho, após os processos de industrialização, tem um aspecto mais humano, se comparado ao do século passado. As atividades que antes eram desenvolvidas em chão de fábricas insalubres e em linhas de montagem contínuas foram forçosamente trocadas por processos de trabalho mais modernos e marcados por contratos temporários e flexibilizados, nos quais o indivíduo é o responsável por sua própria carreira. Contudo, essas mudanças não foram exatamente favoráveis aos trabalhadores. De acordo com Dejours (2000) situações de trabalho geradoras de elevado nível de sofrimento criam no indivíduo a capacidade de lidar com o seu sentimento e continuar trabalhando, ou seja, o indivíduo acaba passando por processo doloroso de confronto até consigo mesmo, relegando suas condições de trabalho a um plano escondido e silencioso, utilizando essa estratégia para lidar com o seu sofrimento. Tal perspectiva fez com que se percebesse a necessidade de avaliar não apenas os dados visíveis que contribuem para o sofrimento, mas analisar a situação do ponto de vista psicossomático.

Se o trabalho hoje não se constitui apenas de uma necessidade de subsistência, mas também de aceitação e participação no meio social, pode-se destacar então, a partir dessa visão, os conflitos a que são submetidos os trabalhadores e avaliar o nível de desgaste psicológico decorrente desse processo.

Para Enriquez (2006) as organizações modernas apresentam-se como um lugar fértil, o único ambiente promotor de realização, de desejos e projetos, em que 
os indivíduos são reconhecidos, gratificados e aplaudidos, postos em confronto com a sua própria identidade. É nesse imaginário que os indivíduos trabalham e lutam diariamente impelidos a competir entre si e a garantir a sua fatia do "bolo", que para eles é tão somente o significado de sua própria existência.

Obviamente o trabalho constitui-se não só de fonte de subsistência, conquistas, reconhecimento pessoal e participação social, mas na maioria das vezes, de fonte de opressão, exploração, discriminação e exclusão dos indivíduos, alterando a sua psique e comprometendo a sua saúde física e mental. Embora hoje, os profissionais tenham mais participação nas decisões e nos processos de criação, o fato é que outras tantas exigências atreladas ao mundo do trabalho corroboram para que este também venha a se constituir de fonte de sofrimento sob qualquer prisma de análise.

É com essa visão que esta pesquisa pretende analisar os fatos geradores de sofrimento no trabalho dos técnicos de laboratório da Faculdade de Medicina da Universidade de Brasília - FMD/UnB, considerando as bases teóricas desenvolvidas pela psicodinâmica do trabalho, de maneira a contribuir no sentido de analisar a partir da visão da psicodinâmica do trabalho, a percepção dos técnicos de laboratório da FMD/UnB, quanto a vivência de sofrimento no ambiente laborativo.

A necessidade de se manter num mercado cada vez mais competitivo e alcançar as metas estipuladas nos planos estratégicos das organizações faz com que estas se preocupem cada vez menos com a saúde dos trabalhadores e exijam cada vez mais resultados. Dos indivíduos presentes nas organizações é exigido, após uma carga horária de trabalho excessiva, que eles ainda consigam se manter constantemente informados, preparados e com capacidade altíssima de criação e solução de problemas. O trabalhador deixou de ser um mero executor e passou a compor o capital intelectual da empresa. É ele o responsável em gerar conhecimentos idéias e inovações com o objetivo de aprimorar constantemente as atividades da organização, seja na melhoria dos processos ou no resultado final do seu produto ou serviço.

Esse desejo de ser reconhecido pela organização e pela sociedade faz com que o indivíduo busque constantemente a excelência e a flexibilidade em suas ações, mesmo que isso comprometa o convívio familiar e o tempo para o lazer e o descanso, palavras de ordem para uma vida saudável. De acordo com Freitas (2000) ser flexível tornou-se o sonho dourado das empresas e consegui-lo tornou se 
uma necessidade desesperadora. Essa idéia é assimilada pelos indivíduos e ser flexível e excelente é o preço a ser pago para se atingir o podium, porém, não existe podium para todos, mas um alto nível de exaustão e fadiga que implica diretamente no adoecimento físico e mental dos indivíduos.

Para Freitas (2000) as empresas propiciam uma identidade social privilegiada aos indivíduos e thes dão a sensação de pertença e inclusão, de conquista de status e um sentido para a sua existência, no intuito de alcançar esse resultado. Porém o indivíduo deve aderir aos valores das empresas em detrimento dos seus próprios valores e se comprometer com os objetivos dela mesmo que isso implique a perda de sua própria personalidade. Esse discurso dominante gera conflitos e estafa que resultam em sofrimento no trabalho.

Porém a retórica de que o capital humano é o principal produto das organizações não pode mais ser compreendida como uma falácia nos meios organizacionais, mas como uma necessidade de se conhecer profundamente a força de trabalho e promover programas que permitam uma vida laboriosa com mais qualidade e dignidade para os trabalhadores. De acordo com Siqueira (2006) a empresa acaba ocupando espaço tão intenso na vida do indivíduo que ele começa a achar natural todas as renúncias feitas para o bem da empresa. Toda a sua vida pessoal acaba sendo prejudicada, assim como suas relações, que ficam restritas àquelas estabelecidas dentro da empresa. Sobre esses fatos Freitas (2000) afirma que na busca da excelência e do sucesso, quando fracassa, o indivíduo torna-se um morto-vivo, sem identidade e auto-imagem, um ser que não reconhece a si mesmo.

Objetivando definir as causas de sofrimento no trabalho, analisar as relações de trabalho envolvendo docentes e servidores técnicos de laboratório, verificar e propor melhorias nas condições de trabalho nos laboratórios da FMD/UnB e partindo do pressuposto de que a Universidade de Brasília - UnB sofre com a escassez de recursos e políticas que visem melhorias nas condições de trabalho dos indivíduos e, com base também no fato de que o quadro de pessoal dessa Instituição está cada vez mais escasso, gerando sobrecarga de trabalho para os profissionais em atividades, este trabalho pretende: mostrar as reais condições de trabalho dos técnicos de laboratório no âmbito da Faculdade de Medicina, salientar as principais deficiências em relação à infra-estrutura, máquinas e equipamentos disponíveis para as atividades laborativas e avaliar os aspectos subjetivos que resultam em sofrimento no trabalho para os indivíduos. 
De acordo com Dejours (2000) "o sofrimento é inevitável e oblíquo. Ele tem raízes na história singular de todo sujeito, sem exceção. Ele repercute no teatro do trabalho ao entrar numa relação cuja complexidade já vimos com a organização do trabalho". Se o sofrimento é inevitável e oblíquo, é possível interferir para a sua erradicação? Existe a possibilidade da descoberta de uma vacina que possa definitivamente eliminá-lo? Está claro que não, mas está claro também que as organizações podem e devem lançar mão de recursos e ferramentas capazes de minimizar os processos que geram sofrimento. Contudo, organizações como a Universidade de Brasília, têm um papel singular para a sociedade, ela é promotora de conhecimentos e aprendizados cada vez mais complexos, suas pesquisas interferem no desenvolvimento social e humano, mas tudo isso ocorre sem que ela perceba que para atingir os seus objetivos é necessário investir no capital humano.

Os indivíduos diariamente dedicam seu tempo, força física e intelectual e sentem-se importantes na medida em que realizam os objetivos da Instituição e os assimilam como seus próprios. Sobre isso, Siqueira (2006) observa que as estratégias das organizações para garantir tal comprometimento é assegurar que haja a identificação dos indivíduos com os seus objetivos e que esses desejem se manter membros eficientes e capazes de realizá-los. A sensação de pertença a um organismo é de vital importância para os indivíduos que mesmo com condições precárias de trabalho realizam diariamente os objetivos da Instituição e se empenham em contribuir para que ela atinja seus objetivos.

O papel principal desta pesquisa é contribuir para que a administração superior e a área de recursos humanos da UnB, trabalhem juntas no sentido de inserir no seu planejamento, estratégias políticas que visem á melhoria das condições de trabalho e por conseqüência a qualidade de vida dos trabalhadores. 


\section{2- Fundamentação teórica}

A partir da leitura de publicações, artigos científicos e pesquisas empíricas, sobre temas relacionados ao sofrimento no trabalho, e partindo dos seguintes tópicos: o imaginário organizacional moderno, prazer e sofrimento no trabalho/psicodinâmica do trabalho e a banalização da injustiça social esta pesquisa pretende verificar as causas de sofrimento no trabalho dos técnicos de laboratório da Faculdade de Medicina da UnB.

\section{1- As relações de trabalho nas organizações contemporâneas}

Vieira (2005) partindo das idéias de Marx admite que o trabalho diferencia o homem dos animais. Para executar uma tarefa o homem intencionalmente planeja a sua ação antevendo, diferenciando-se desse modo da natureza instintiva do animal.

Ainda de acordo com o autor, o homem ao atuar sobre o mundo externo, transforma-o e altera sua própria natureza e afirma que, com o advento do modo de produção capitalista o trabalhador, que antes era livre, passa a vender sua força de trabalho ao capital, produzindo valores de troca de em vez de valores de uso, o que resulta no processo de mais-valia, fator este determinante para o atual modo de acumulação capitalista.

Já para a autora Albornoz (1986 apud VIEIRA, 2005) ela argumenta que os diversos significados atribuídos ao trabalho dependem da cultura, da sociedade e da área do conhecimento. O trabalho pode até significar então: atividade, exercício, incômodo, dificuldade e sofrimento. Destaca ainda, que o trabalho imputa uma tendência para um fim, demandando esforço físico e ou intelectual.

Albornoz (1986 apud VIEIRA, 2005) certifica que o trabalho humano é mais visível quanto mais clara for a intenção e a direção do seu esforço, sendo simultaneamente, o esforço e resultando num processo e ação, diferenciando-se dos animais pela consciência e intencionalidade e igualando-se a estes pela necessidade de sobrevivência. Entretanto, aponta que a liberdade é o que distingue definitivamente o homem dos animais, pois pode realizar seu trabalho de várias 
maneiras, adequando o trabalho ao seu próprio ritmo, mesmo vivendo numa relação de subordinação.

Assim, observa que o trabalho pode ser sinônimo de atividade, identidade, criação e realização, onde o homem imprime sua marca e se reconhece como autor de sua obra. Na modernidade, o trabalho é o modo como o indivíduo dá sentido à sua vida, tendo dificuldade na busca desse sentido se não for pela via do trabalho.

Autores como Guareschi e Grisci (1993 apud VIEIRA, 2005) entendem o trabalho como uma ação transformadora, consciente e desejante, que o trabalhador exerce sobre a natureza, com ou sem auxílio de uma máquina. Desta forma o trabalhador é o sujeito do trabalho e como tal, se diferencia da máquina, sobressaindo-se a esta.

Para Blanch (1996 apud VIEIRA, 2005) ele sustenta que o trabalho é uma instituição tão antiga quanto à própria humanidade, sendo sua trama e seus atores modificados ao longo do tempo e dos espaços socioculturais, sendo também metamorfoseados o sentido, o valor, o significado e as funções que the são atribuídas.

O autor ainda afirma que a noção de trabalho, como categoria central, adveio da sociedade industrial, que cunhou o trabalho como uma experiência humana individual e coletiva que direciona a moral, o direito, a política, a cultura e o humanismo.

Um estudo transcultural conduzido pelo grupo MOW (conforme citado por Blanch 1996 apud VIEIRA, 2005) indica a centralidade do trabalho para as categorias sexo, idade e país. Os aspectos mais desejáveis em um trabalho, apontados em ordem de importância, são: o interesse pela atividade desempenhada, a boa remuneração, a autonomia, o ambiente de trabalho, a higiene e segurança, a adequação da tarefa às próprias competências, as oportunidades de aprender, a variedade do trabalho, o horário, o meio físico e as oportunidades de promoção.

No entanto, Dejours (1999 apud VIEIRA, 2005) pondera que o trabalho pode ser entendido como um território ambivalente, uma vez que tanto pode dar origem a processos de alienação, e mesmo de descompensação psíquica, quanto pode ser fonte de saúde e instrumento de emancipação.

Tal afirmação é coerente com a visão de Antunes (1999 apud VIEIRA, 2005) que, ao investigar os sentidos do trabalho para a classe trabalhadora, afirma que só 
é possível aos trabalhadores terem uma vida cheia de sentido fora do trabalho, se conseguir que a vida no trabalho seja dotada de sentido.

Em Ferreira (2003 apud VIEIRA, 2005) ele afirma que o trabalho possibilitou ao homem garantir sua sobrevivência, sendo universal e confundido com sua própria história. O trabalho é uma atividade que media a relação homem e ambiente, ou seja, ao buscar transformar o ambiente para satisfazer suas necessidades materiais e espirituais, os indivíduos, como resultados dos efeitos da própria ação, são "transformados" por ele. Desse modo, o trabalho presta-se ao papel de ser forjador da cultura, responsável pelo desenvolvimento individual, das sociedades e, portanto, inalienável à condição humana.

Siqueira (2006) afirma: "As empresas colaboram com o desenvolvimento econômico global e também estão permeadas, implícita ou explicitamente, por dimensões que afetam substancialmente a vida das pessoas, as quais se relacionam direta ou indiretamente com elas". A importância das organizações para a sociedade de forma generalizada é inegável. São elas que promovem o desenvolvimento das nações, são elas que propiciam o crescimento econômico e financeiro da sociedade. Contudo, também são elas as maiores responsáveis pela destruição do meio ambiente e por arquitetarem e construírem "coisas" que em geral alteram drasticamente o modo de vida das pessoas, muitas vezes, de forma negativa. Como dito por Aubert e De Gaulejac (1991 apud Freitas 2000) são as organizações que preenchem o vazio dentro de uma sociedade e mediam as relações sociais, na família e na comunidade. As organizações lêem o que se passa a sua volta e elaboram respostas que sirvam aos seus objetivos. As organizações criam uma imagem de perfeição para a sociedade e se mostram como a mãe dedicada e protetora disposta a atender os desejos e sonhos dos "filhos", estimulando a afetividade dos indivíduos em relação a elas.

Para Siqueira (2006) as práticas de recursos humanos são utilizadas pelas organizações para seduzir e internalizar os valores e crenças da empresa nos funcionários. Os trabalhadores por sua vez são parte constituinte de uma sociedade dentro e fora da organização e é nesse contexto que conseguem a multiplicidade desses valores e crenças criando a sociedade organizacional. Ao passo que antes a sociedade tinha uma definição cultural sancionada pelos indivíduos, no mundo globalizado a vida em sociedade e a cultura social passaram a ser definida pela mente organizacional e conduzida conforme os seus próprios interesses. 
Enriquez (2006) afirma que as empresas prendem os indivíduos em armadilhas criadas pelos seus próprios desejos narcisísticos em busca de reconhecimento e se mostra capaz de responder e transformar esses desejos em realidade. É possível afirmar, sem risco de contradição, que o mundo atual se tornou sádico.Os antigos valores de mérito, trabalho, honra, prestígio e "a herança histórica, usada pelo capitalismo, inclusive a honestidade, a integridade, a responsabilidade, 0 cuidado no trabalho, o respeito aos outros" Castoriadis (1996 apud Enriquez, 2006) foram desvalorizados em prol de um único valor: o dinheiro.

Ainda de acordo com Enriquez (2006) o poder demandado pelo dinheiro traz drásticas conseqüências ao nível coletivo, tais como a dissolução do vínculo social, exclusão ou "desvinculação social", competição exacerbada, pilhagem do planeta, enfraquecimento dos movimentos sociais, diminuição das lutas sindicais e, por outro lado, importância crescente das empresas, que querem ser "as instituições divinas" incitando os indivíduos a se integrar, a se identificar com as organizações das quais fazem parte e idealizá-las, colocando os valores organizacionais - seu próprio ideal do ego - no lugar dos seus próprios valores, transformando-os em instrumentos submissos, dóceis e, sobretudo, fazendo com que eles acreditem que são responsáveis enquanto sujeitos e que estão a caminho da autonomia, são donos de seus próprios destinos. Nessa realidade o indivíduo passa a viver no imaginário organizacional deixando de lado seu eu psíquico, projetando os valores organizacionais onde o poder emana do dinheiro, onde a moeda assume o papel principal e o ser humano é totalmente desvalorizado.

Essa renúncia mesquinha da própria identidade em prol de um valor frágil e subjetivo é a principal causadora das violações dos direitos humanos e das catástrofes do mundo atual, já que sem a seleção natural o poder ficou concentrado nas mãos de poucos que submetem e escravizam a maioria, sendo o resultado disso a competição desmedida e muitas vezes injusta.

O indivíduo larga-se na mão de um sistema dominante, incapaz da lucidez que o define como "gente", incapaz de pensar e agir como dono do seu próprio destino, passando a atuar como um mero objeto das organizações, cuja finalidade sempre é a alta lucratividade e o poder emanado dos recursos financeiros. Nesse contexto o Estado apresenta-se como uma instituição omissa, imóvel e corruptível cujos valores também foram sobrepujados pelos valores organizacionais, o que o torna incapaz de agir com determinação e de impor limites para o papel das 
organizações no meio social. Se antes as organizações existiam apenas para oferecer produtos e serviços, hoje elas controlam a economia, as decisões políticas e interferem diretamente na vida dos indivíduos, modificando os comportamentos e influenciado as relações interpessoais.

Produtividade, excelência, flexibilidade, eficácia e eficiência são palavras de ordem no mercado de trabalho. Para ter um alto nível de empregabilidade os indivíduos precisam adotar isso como regra, o que torna o trabalho um fardo cada vez mais pesado e doentio. Se é sofrível não ter emprego, também é estressante trabalhar com a sensação de insegurança, tendo que ser o melhor, o mais produtivo, o mais eficiente, o "trabalhador modelo". Algumas empresas utilizam se de processos que identificam o "trabalhador modelo", expondo os indivíduos em vitrines comerciais, como exemplos a serem seguidos. $O$ indivíduo que não consegue atingir essas inúmeras exigências e alcançar o podium tão almejado sente-se incapaz e com baixa estima, enquanto o indivíduo que o atinge não consegue mais viver sem essa colocação e sofre desgastes físicos e mentais para ser o "melhor". Essa cultura é imposta pelas organizações tanto públicas quanto privadas, não sendo diferente em Instituições de Ensino como a UnB.

Siqueira (2006) afirma que a busca incessante por sucesso profissional e reconhecimento pode levar os indivíduos, além do trabalho excessivo, ao adoecimento psicológico, tendo como conseqüências graves problemas de saúde. Não é fácil atingir metas o tempo inteiro, ser capaz de cumprir uma carga horária de trabalho excessiva e ainda se manter informado e preparado para as possíveis mudanças no mercado. Ao fazer isso o trabalhador abre mão do convívio familiar, da educação dos filhos, da convivência com os amigos e da vida conjugal. Tais ações contribuem para que as organizações participem mais ativamente da vida familiar. Elas entram nos lares do mundo inteiro pelos meios de comunicação, interferem na educação das crianças, ditam modelos de beleza, comportamento e atitudes e a sociedade alienada não lhes emite qualquer restrição.

A necessidade de se manter num mercado cada vez mais competitivo e exigente impõe uma carga horária muitas vezes impraticável, obrigando o indivíduo a perder noites de sono e a viver numa inquietação angustiante, teoria facilmente comprovada pelos números registrados de casos de infarto fulminante existentes. Aos trabalhadores hoje, não se permitem momentos de relaxamento e prazer, dormem mal e trabalham até mesmo durante as refeições, apressadas e mal 
digeridas. A insegurança, o medo de perder o emprego, o medo de não atingir as metas estipuladas nos planos estratégicos das organizações, fazem os indivíduos se empenharem ao máximo, chegando a ponto da exaustão física e mental.

$O$ fato é que as organizações exigem cada vez mais comprometimento dos seus colaboradores e os descartam quando percebem que eles não são mais capazes de atingir os objetivos dela ou quando eles não têm a aparência jovem e dinâmica que espelha o mito de juventude eterna.

Se os valores propostos pela sociedade são os valores disseminados pelas organizações, então é necessário ter muito dinheiro e muito mais que os outros para ser visto e percebido como um indivíduo bem-sucedido, que alcançou o sucesso a partir de seus próprios esforços, com muito sacrifício e dedicação. $O$ trabalhador age como um super-homem, impondo a si mesmo uma carga horária desumana e que compromete a sua saúde, Freitas (2000 apud SIQUEIRA, 2006) afirma que isso acontece não só em razão da competitividade, mas pelo fato de que o indivíduo se submete a isso com a expectativa de alcançar cargos cada vez mais altos os quais o tornem admiráveis e respeitáveis diante dos outros.

\section{2- Considerações acerca da Psicodinâmica do Trabalho}

A psicodinâmica do trabalho estuda as relações dinâmicas entre organização do trabalho e processos de subjetivação - atribuição de sentido, construído com base na relação do trabalhador com sua realidade de trabalho, expresso em cuidar de pessoas, sentir e agir individualmente ou coletivos (Mendes, 2007).

É de suma importância a inserção do trabalhador de modo coletivo na organização, pois desta forma se torna mais eficaz a mudança da realidade de trabalho nas organizações, de maneira a proporcionar ao trabalhador mecanismos para amenizar o sofrimento decorrente da busca pela excelência e da produtividade.

No mundo globalizado em que vivemos hoje, com a necessidade das organizações em competir por espaço, produtividade e continuidade no mercado, faz com que o trabalhador se depare com exigências e imposições que acabam por provocar situações que desencadeiam no sofrimento dos indivíduos. Desta maneira, a psicodinâmica do trabalho requer também o desenvolvimento de ações que proporcionem ao trabalhador uma forma de clínica do trabalho, a reconstruir e 
desenvolver estratégias que permitam confrontar as situações provocadoras de sofrimento, de maneira a buscar prazer e consequentemente a saúde. Esta realidade existente entre trabalhador e organização acaba por demonstrar a relação/encontro entre a psicodinâmica e a psicopatologia do trabalho.

A Psicodinâmica do Trabalho privilegia a inter-relação entre o sofrimento psíquico, oriundo dos conflitos entre o sujeito e a realidade de trabalho e as estratégias de mediação empregada pelos trabalhadores para lidar com o sofrimento e transformar o trabalho em fonte de prazer, Mendes (2007). Isso explica ou justifica a negação ou aceitação do sofrimento que ocorre nos ambientes organizacionais e que são percebidas como estratégias individuais ou coletivas utilizadas pelos indivíduos para se adaptarem e se manterem nessas organizações.

"O prazer-sofrimento no trabalho tem sido estudado pela psicodinâmica desde os anos 80, como um constructo dialético". Prazer é vivenciado quando o trabalho favorece a valorização e reconhecimento, especialmente pela realização de uma tarefa significativa e importante para a organização e a sociedade. Tal reconhecimento e valorização são de fundamental importância segundo as pesquisas realizadas por Mendes de Linhares (1996) e Mendes e Abrahão (1996).

\footnotetext{
O trabalho contém vários elementos que influenciam a formação da autoimagem do trabalhador que, por sua vez, é razão para sofrimento. Tais pesquisas revelam que situações de medo e de tédio são responsáveis pela emergência do sofrimento, que se reflete em sintomas como a ansiedade e insatisfação (Dejours, 1987).
}

Dejours (2000) afirma ainda, que o sofrimento além de ter origem na mecanização e robotização das tarefas, nas pressões e imposições da organização do trabalho, na adaptação à cultura ou ideologia organizacional, representada nas pressões do mercado, nas relações com os clientes e com o público, é também causada pela criação das incompetências, significando que o trabalhador se sente incapaz de fazer face às situações convencionais, inabituais ou erradas quando acontece a retenção da informação que destrói a cooperação.

A psicodinâmica do trabalho é oriunda da psicopatologia do trabalho, que emergiu na França por volta dos anos 50/60, tendo como principais pesquisadores Lê Guillant, Veil, Sivadon, Fernandez-Zoila e Begoin. Os estudos desses pesquisadores visavam à investigação das adversidades do trabalho partindo do 
pressuposto que tais adversidades desencadeavam distúrbios psicopatológicos. (Dejours, 2004).

Nos anos 80, o autor se distância do modelo casual de pesquisa e cria a psicodinâmica do trabalho, sustentando que nenhum tipo de trabalho gera doença mental. Nessa concepção, o sofrimento no trabalho origina-se do conflito entre a organização do trabalho e o funcionamento psíquico do sujeito (Dejours, 2004).

Dejours (2004 apud Vieira, 2005) denomina a psicodinâmica do trabalho como a "análise do sofrimento psíquico resultante do confronto dos homens com a organização do trabalho, ou ainda, como a análise psicodinâmica dos processos intersubjetivos mobilizados pelas situações de trabalho".

O percurso desta abordagem caracteriza-se por três fases. A primeira fase, ainda sob a denominação de psicopatologia do trabalho, era centrada no estudo da origem do sofrimento e nas conseqüências do confronto do psiquismo do trabalhador com a organização do trabalho. Devido às precárias condições de trabalho da época e da predominância do modelo taylorista, os estudos buscavam compreender o sofrimento e as estratégias defensivas individuais e coletivas utilizadas pelos trabalhadores para lidar com o sofrimento.

A segunda fase centra-se no estudo da normalidade, aqui entendida como sinônimo de saudável e não de normal. Investiga como os trabalhadores conseguem manter a saúde, evitar o adoecimento, manter a produtividade e, sobretudo, busca entender como o trabalho pode propiciar vivências de prazer, segundo (Dejours e Abdoucheli, 1994; Mendes, 2004 apud Vieira, 2005).

Nesta fase, o trabalho deixa de ser apenas sinônimo de sofrimento, mas também lugar de realização, pois de acordo com Dejours (1999 apud Vieira, 2005) e Mendes (2004 apud Vieira, 2005) a conquista de a identidade faz-se em dois registros: no amor, como construção da identidade no campo erótico, e no trabalho, dando acesso à construção da identidade no campo social.

Assim, é lícito afirmar que o trabalho pode ser estruturante para a construção do sujeito, contudo, torna-se perigoso para o psiquismo quando se opõe à sua livre atividade, não permitindo a descarga pulsional a fim de diminuir a carga psíquica. Logo, um trabalho que permite a diminuição da carga psíquica é equilibrante, porém, quando o mesmo se opõe a essa diminuição torna-se fatigante (Dejours, 1994).

O autor afirma que para haver a transformação de um trabalho fatigante em um trabalho equilibrante, faz-se necessário flexibilizar a organização do trabalho, de 
modo a propiciar maior liberdade ao trabalhador para rearranjar se de modo operatório, identificando ações capazes de propiciar vivências de prazer.

A terceira etapa da disciplina investiga a psicodinâmica do reconhecimento como um dos meios possíveis para vivenciar o prazer. A dinâmica do reconhecimento possibilita ao sujeito a conquista da identidade no campo social, que é viabilizada pela relação que o sujeito mantém com o real através do julgamento do outro (Dejours, 1999 apud Vieira, 2005).

Observa-se então, que o desafio real para a psicodinâmica do trabalho, é definir ações suscetíveis de modificar o destino do sofrimento e favorecer sua transformação, e não sua eliminação. Quando o sofrimento pode ser transformado em criatividade, ele traz uma contribuição que beneficia a identidade, aumenta a resistência do sujeito ao risco de desestabilização psíquica e somática e funciona como um mediador para a saúde. Quando ao contrário a situação, as relações sociais de trabalho e as escolhas gerenciais empregam o sofrimento, o trabalho funciona como um mediador para a desestabilização e fragilização da saúde (Dejours e Abdoucheli, 1994 apud Vieira, 2005 ).

Para Dejours (2000) por trás das belas fachadas e vitrines das empresas, existe um mundo de sofrimento dos que trabalham e que de alguma forma deixaram de existir. Embora hoje, quase todos os trabalhos sejam desenvolvidos por indivíduos de mãos limpas e bem vestidos ele não é menos arriscado que o trabalho desenvolvido em fábricas sujas e insalubres que expõem a saúde dos indivíduos. Nesse contexto, o trabalhador ainda precisa se adaptar a cultura e ideologia organizacional às imposições de horário e ao ritmo acelerado e às exigências de desenvolvimento de competências, eficiência e aprendizagem constante.

Para descrever sofrimento no trabalho há que se considerar os fatos que elucidam tal sofrimento. Dentre eles Dejours (2000) conclui que o medo da incompetência pode caracterizar sofrimento. O indivíduo é exposto a situações que colocam em cheque suas capacidades e suas habilidades, situações estas alheias à sua vontade e incompatíveis com o desenvolvimento eficaz das tarefas - isso é comum nos ambientes organizacionais - o trabalhador geralmente é incitado a desenvolver e a produzir sem as ferramentas e instrumentos adequados. Muitas vezes fica exposto a riscos, mas nem por isso deve deixar de alcançar os resultados pretendidos pelas organizações, ou seja, os fins justificam os meios e o importante é produzir e alcançar as metas em qualquer circunstância. Contudo, trabalhar nesse 
ambiente conflituoso exige cada vez mais criatividade e capacidade de solucionar problemas de maneira quase mágica, o resultado é a necessidade de uma constante superação de si mesmo.

Para Dejours (2000) outro ponto que acarreta em sofrimento é a pressão dentro dos próprios ambientes provocados pelas chefias ou pelas equipes. As relações no meio organizacional são cada vez mais competitivas e conflitantes, nas quais os valores éticos e de responsabilidade foram deturpados em prol do interesse organizacional. De acordo com Mendes (2004) as empresas exigem um profissional competente e competitivo, polivalente e criativo, mas nem sempre fornecem um suporte organizacional promotor da saúde no trabalho.

Para exemplificar tal fato pode-se citar o ocorrido recentemente com o leite brasileiro. Os trabalhadores de indústrias de pasteurização sabiam que os aditivos químicos postos no leite causavam prejuízos à saúde dos consumidores, mas por receio de perder o emprego não agiam como "delatores" e tentavam negar a sua culpa nas ações promovidas pela empresa. Contudo, no discurso de um dos trabalhadores apresentado pela mídia, ele descrevia os sentimentos que inferem a existência do sofrimento, mesmo não tendo partido dele a decisão sobre os aditivos, de alguma forma ele participava do processo e se tornava conivente com a situação ao se omitir, embora, internamente, isso o contrariasse e lhe causasse a sensação de angústia.

Esse fato não é novo e nem isolado e tornou-se rotina no mundo moderno. Empresas que se dizem preocupadas com o meio ambiente e atentas para a responsabilidade social promovem, por meio de ações irresponsáveis, a proliferação de muitas doenças e a destruição do meio ambiente. Na verdade a única preocupação delas é com o lucro, independentemente do custo trazido para a sociedade e não importam as multas aplicadas pelo Estado ou a imagem negativa imposta pela mídia, elas geralmente têm o poder de contornar a situação e passar por tudo sem maiores prejuízos para os seus acionistas. Nesse contexto é fácil imaginar o sofrimento dos trabalhadores quando executam suas tarefas cientes de que estão prejudicando a si mesmo e aos outros, mas angustiados com medo de perder o emprego e a sustentabilidade da família. De fato não existem realmente empresas solidárias, assim como não existem empregadores preocupados com a saúde e o bem-estar dos trabalhadores ou da sociedade em geral, o que realmente 
existe é uma competitividade insana das organizações para se manterem no mercado.

Outro dado que merece atenção é a falta de respeito às leis e a regras de contratação de trabalhadores. Não há fiscalização também para isso e as empresas se aproveitam desse fato, contratando mão-de-obra sem as garantias legais, expondo cada vez mais os indivíduos a situações de risco tais como: insalubridade, periculosidade e carga horária excessiva de trabalho. Os contratos de terceirização de mão-de-obra criados pelas empresas são a prova de que ninguém quer ser o responsável pelos trabalhadores, ficando os indivíduos jogados à própria sorte. Excetuando-se os cargos estratégicos das altas gerências ou funções de confiança, a maioria das organizações tanto públicas quanto privadas terceirizam a mão-deobra operacional. Essa situação de contrato é ponto crucial para que os indivíduos se sintam cada vez mais inseguros e fragilizados, afinal não sabem a quem recorrer, não conseguem identificar nem mesmo o seu empregador. Por outro lado, organismos que tinham o papel de defesa dos trabalhadores, tais como sindicados e associações, ao longo dos anos foram perdendo força e respeitabilidade, restando para o trabalhador o direito de ficar calado e a necessidade de se submeter às exigências do mercado de trabalho.

Ser empreendedor, melhorar os processos, ter capacidade extrema de realização e solução de problemas, tudo isso é cobrado diariamente dos trabalhadores, e eles esperam o reconhecimento advindo de suas próprias realizações. Dejours (2000) afirma que o reconhecimento não é uma reivindicação secundária dos que trabalham, mas um fator decisivo na dinâmica da mobilização subjetiva da inteligência classicamente designada pela expressão "motivação no trabalho". Para ele os trabalhadores em sua maioria dispensam energia, paixão e investimento pessoal na execução de suas atividades e isso merece ser reconhecido, mas no geral passa despercebido ou é negado, acarretando um sofrimento perigoso para a saúde mental do trabalhador.

As pesquisas de Dejours (2000) comprovam que a falta ou a negação do reconhecimento fazem com que o trabalhador crie para si mecanismos de defesa ou a negação do próprio sofrimento a que está exposto, e ele mesmo se pergunta como pode o indivíduo não enlouquecer sofrendo pressões diariamente e fingindo uma normalidade onde ela não existe? Isso lhe dá uma interpretação de que a 
normalidade não implica ausência de sofrimento, mas a dura luta individual ou coletiva para negar esse sofrimento.

É possível dizer que atualmente o número de vagas é insuficiente para a quantidade de homens e mulheres com capacidade e necessidade de trabalho e o medo de não ser empregável ou de perder o emprego é utilizado como chantagem pelas organizações para manter os indivíduos sob "cabrestos", somando-se a isso a falta de ação dos sindicatos ou dos agentes de defesa, o que impossibilita qualquer reação contra essas adversidades. Para Dejours (2000), no entanto, não existe falta de trabalho, o que existe é uma visão doentia de lucro que determina o enxugamento dos quadros e intensifica as atividades e a carga horária dos que permanecem empregados. Para o trabalhador resta apenas aceitar a situação já que reclamar sozinho causa a impressão de incompetência ou desmotivação para execução das atividades, o que os deixa inibidos diante dos colegas e incapaz de expor o seu sofrimento.

\section{3- Aspectos Metodológicos}

Foi realizada uma pesquisa qualitativa e descritiva, na qual procurou-se descrever o sentimento dos servidores técnicos de laboratório da Faculdade de Medicina da UnB, quanto aos fatores que causam sofrimento no trabalho, podendo estabelecer correlações entre variáveis e definir sua natureza, sem, no entanto, se comprometer a explicar os fenômenos que descrevem e interferem nas questões opinadas pelos participantes da pesquisa, Vergara (2004). A pesquisa baseia-se quanto aos fins em exploratória e descritiva, por não se verificar a existência de pesquisas com referência a técnicos de laboratório da Faculdade de Medicina da UnB e pela exposição da opinião dos servidores dos laboratórios que compõem a faculdade sobre as causas do sofrimento na instituição; quando aos meios, em bibliográfica e de campo. Com referência à parte bibliográfica, procura-se dar ênfase a publicações, artigos científicos, periódicos, dentre outros, enfatizando os seguintes tópicos: o imaginário organizacional moderno, prazer e sofrimento no trabalho/psicodinâmica do trabalho e a banalização da injustiça social, os quais servirão de suporte no que se refere à fundamentação teórica e metodológica do estudo. No que se refere à pesquisa de campo, serão coletados dados na Instituição 
em que ocorre o fenômeno e que dispõe de elementos para explicá-lo (Vergara, 2004).

Por ser de cunho estritamente pessoal e peculiar a determinado ambiente, o assunto pesquisado foi encaminhado sob a forma de entrevistas nas quais procuraremos observar as percepções dos servidores quanto às causas do sofrimento no trabalho e, a partir dessas respostas tentou-se identificar quais os fatores que podem amenizar esse sofrimento de maneira a dar compreensão dos mesmos pelos entrevistados.

\section{1- Participantes da Pesquisa}

Participaram da pesquisa 15 servidores efetivos, lotados nos diversos laboratórios pertencentes à Faculdade de Medicina (FMD) da Fundação Universidade de Brasília (FUB) com nível de escolaridade média e superior que se integraram às entrevistas através da técnica de acessibilidade.

\section{2- Instrumentos da coleta de dados}

Foi utilizada a técnica de entrevistas semi-estruturadas que permite a estreita relação entre entrevistador e entrevistados. As entrevistas ocorreram por pautas, constituídas de perguntas nas quais se agendou pontos referentes ao assunto, no intuito de dar maior profundidade à pesquisa, conforme (Vergara, 2004). As perguntas foram individualizadas para cobrir tópicos que se refiram às formas de sofrimento citadas na obra de Dejours (2000) e que permitiam fazer as modificações necessárias durante a sua aplicabilidade, tendo em vista os aspectos peculiares relacionados ao trabalho e ao próprio entrevistado e seus respectivos ambientes de trabalho, já que a Instituição se compõe de laboratórios de diferentes áreas de atuação dos profissionais. 


\section{3- Procedimentos da Coleta de dados}

A pesquisa foi realizada com autorização da Direção da $\mathrm{FM} / \mathrm{UnB}$ e dos respectivos chefes imediatos dos participantes, de forma transparente, com horário e local definidos, com a anuência da Instituição e dos entrevistados, com o compromisso por parte dos entrevistadores de haver total sigilo sobre o conteúdo das informações coletadas durante o processo e omitindo-se os nomes dos indivíduos e um posterior contato dos entrevistadores com os entrevistados para informações sobre os resultados obtidos após a sua conclusão.

\section{4- Análise dos dados}

A análise de conteúdo das entrevistas e categorização dos dados foi realizada de maneira a se fazer uma correlação com o referencial teórico pesquisado. As entrevistas foram conduzidas levando-se em consideração a linguagem do sujeito e a utilização de técnicas como: associação livre, deflexão e estimulação, objetivando investigar o que se refere o contexto de trabalho, o respeito aos sentimentos no trabalho, os modos de enfrentar a organização e as patologias sociais decorrentes da organização do trabalho (Mendes, 2007).

As entrevistas foram desenvolvidas de maneira a oferecer uma compreensão de como a pesquisa foi realizada no âmbito dos laboratórios da Faculdade de Medicina da UnB e os dados foram analisados conforme as técnicas descritas por Bardin (1994) onde análise de conteúdo "é um conjunto de instrumentos metodológicos cada vez mais sutis e em constante aperfeiçoamento que se aplicam aos discursos extremamente diversificados".

A análise de conteúdo engloba três pólos cronológicos: a) pré-análise, que é a organização propriamente dita, objetivando sistematizar e operacionalizar as idéias iniciais e possui três objetivos: a escolha dos documentos, a formulação de hipóteses e objetivos e a elaboração de indicadores que fundamentem a interpretação final. b) a exploração do material, que consiste essencialmente em operações de codificação, fase caracterizada por ser de longa duração e fastidiosa; c) tratamento dos resultados obtidos e interpretação onde os resultados são analisados de maneira a serem significativos e válidos, de forma que se possa então 
propor inferências e adiantar interpretações a propósito dos objetivos previstos, ou que digam respeito a outras descobertas inesperadas, e ainda com os resultados obtidos, a confrontação sistemática com o material e o tipo de inferências alcançadas, servirem de base, a outras análises.

Os procedimentos de análise utilizam o processo de categorização que de acordo com Bardin (1994) é uma operação de classificação de elementos constitutivos de um conjunto, por diferenciação e reagrupamento segundo o gênero, com os critérios previamente definidos. A categorização utiliza o critério de semântica (categorias temáticas), sintático (verbos e adjetivos), léxico (classificação das palavras segundo seu sentido com emparelhamento dos sinônimos e dos sentidos próximos) e expressivo (perturbações da linguagem). A categorização é ainda um processo estruturalista e comporta duas etapas: o inventário (isola os elementos) e a classificação (a procura de dar uma certa organização às mensagens).

A análise de conteúdo se bem aplicada produzirá um sistema de categorias que devem possuir as seguintes qualidades: 1 - A exclusão mútua (cada elemento não pode existir em mais de uma disposição); 2- a homogeneidade (o principio da exclusão mútua depende da homogeneidade das categorias); 3-a pertinência (adaptação ao material de análise escolhido); 4- a objetividade e a fidelidade (codificação de maneira semelhante mesmo quando submetidas a várias análises); 5- A produtividade (fornecimento de resultados férteis). 


\section{4- Apresentação e discussão dos resultados}

A apresentação e discussão dos resultados tiveram como finalidade obter a partir das entrevistas semi-estruturadas e individuais, a percepção dos servidores quanto à vivência de sofrimento no trabalho, considerando os aspectos relativos ao contexto organizacional no âmbito da FM/UnB.

No decorrer da investigação os entrevistados foram incentivados a responder questões relativas à sua rotina no ambiente organizacional, atendendo em parte a prescrição analítica da Psicodinâmica do Trabalho. Para tanto, foi desenvolvido um roteiro com 10 (dez) questões considerando os aspectos inerentes às condições, organização e relações socioprofissionais, danos físicos e psíquicos e a percepção dos próprios trabalhadores quanto à vivência de sofrimento.

Quadro 1: Perfil dos entrevistados - Técnicos de Laboratório - Servidores do Quadro Permanente da UnB - Lotados na Faculdade de Medicina

\begin{tabular}{ccl}
\hline Entrevista & Gênero & Escolaridade \\
\hline 1. & $\mathrm{M}$ & Médio \\
2. & $\mathrm{M}$ & Médio \\
3. & $\mathrm{M}$ & Superior \\
4. & $\mathrm{~F}$ & Superior \\
5. & $\mathrm{~F}$ & Superior \\
6. & $\mathrm{M}$ & Superior \\
7. & $\mathrm{M}$ & Médio \\
8. & $\mathrm{~F}$ & Médio \\
9. & $\mathrm{M}$ & Médio \\
10. & $\mathrm{~F}$ & Superior \\
11. & $\mathrm{~F}$ & Superior \\
12. & $\mathrm{M}$ & Médio \\
13. & $\mathrm{M}$ & Médio \\
14. & $\mathrm{M}$ & Médio \\
15. & $\mathrm{~F}$ & Superior \\
\hline
\end{tabular}

Quadro 2: Tempo de Serviço na Instituição

\begin{tabular}{cc}
\hline Tempo de serviço na Instituição \\
\hline Qtde & Anos \\
2 & 0 a 10 \\
1 & 11 a 20 \\
7 & 21 a 30 \\
4 & 31 a 40 \\
1 & acima de 40 \\
\hline
\end{tabular}


Ficou constado que a média de idade dos profissionais entrevistados é de 48,4 anos e que o grupo de servidores em sua maioria tem acima de 29 anos na Instituição e 25 anos no cargo. Sendo que apenas duas servidoras foram admitidas nos últimos 04 anos. Não há praticamente diversidade quanto à idade e tempo de serviço na amostra coletada. Cabe ressaltar que dentro da amostra 02 dos servidores já ultrapassaram o período aquisitivo para aposentadoria e não se manifestaram em relação a esse direito.

\section{1- Condições de Trabalho}

Mendes (2007) considera para avaliação desse tópico a infra-estrutura, apoio institucional, práticas administrativas, ambiente físico: instrumentos, equipamentos, suporte organizacional e práticas de remuneração. Dos 15 entrevistados, 10 queixaram-se das condições precárias, tais como: equipamentos ultrapassados, infra-estrutura inadequada, ambientes com altos índices de insalubridade e ainda, a falta de materiais básicos para a realização das tarefas, bem como a inexistência de equipamentos de segurança, corroborando com a teoria.

A negligência da organização em relação às condições de trabalho certamente gera sofrimento ou alienação e evidenciam sentimentos de frustração e insatisfação nos trabalhadores. De acordo com estudos, a higiene e segurança, as oportunidades de aprender, a variedade do trabalho, são aspectos importantes para uma relação de trabalho saudável. Do ponto de vista da maioria dos técnicos de laboratório da FMD/UnB, esses aspectos são inexistentes na organização, mas ainda assim, eles precisam realizar suas atividades. De acordo com Dejours (2000), o medo da incompetência pode caracterizar sofrimento. O indivíduo é exposto a situações que colocam em cheque suas capacidades e suas habilidades, situações estas alheias à sua vontade e incompatíveis com o desenvolvimento eficaz das tarefas - isso é comum nos ambientes organizacionais - o trabalhador geralmente é incitado a desenvolver e a produzir sem as ferramentas e instrumentos adequados. Muitas vezes fica exposto a riscos, mas nem por isso deve deixar de alcançar os resultados pretendidos pelas organizações, tal prática está implícita na organização pesquisada. 
"As condições não são realmente agradáveis e não são ótimas como deveria ser. Falta uma capela (câmara de fluxo-laminar) uma sala para que fiquemos livres da contaminação de algumas substâncias do laboratório." (Entrevistado n 6)

"Nós fizemos o pedido, mas a UnB nunca disponibilizou pra gente jalecos, óculos de proteção e equipamentos individuais de segurança....até hoje a gente não recebeu." (Entrevistado n 15)

"A maioria dos equipamentos que utilizo no trabalho são muito velhos, alguns não funcionam bem e as paredes estão precisando de pintura." (Entrevistado $n$ 9)

"As condições são um pouco precárias, há deficiência em material e os equipamentos são ultrapassados". (Entrevistado n 13)

"As condições são boas. Eu Não posso reclamar de falta de material, da falta de conforto. Não vou dizer um conforto 100\%, mas o básico eu tenho". (Entrevistado $n$ 12).

"Os equipamentos são obsoletos e os materiais inadequados, mas nós temos que trabalhar assim mesmo!" (Entrevistado n.5)

\section{2- Organização do Trabalho}

Com relação aos aspectos que caracterizam a organização do trabalho, são considerados os elementos prescritos - normas, divisão do trabalho, jornada de trabalho, horários, escalas, prazos e pressão, controles, natureza e conteúdo da tarefa - que no geral regulamentam o funcionamento organizacional 10 servidores alegaram que o trabalho era rotineiro e que as tarefas sofriam descontinuidade por falta de equipamentos ou materiais necessários para a execução, implicando diretamente no resultado, causando frustração nos envolvidos. Outros 05 relataram diversidade e complexidade na realização das tarefas. Contudo, não houve alegações sobre excesso de trabalho, fortes cobranças, fiscalização 
rígida e todos alegaram ter capacidade profissional para realização das suas funções.

Estudos apontam que o trabalho é o modo como o indivíduo dá sentido à sua vida, tendo dificuldade na busca desse sentido se não for pela via do trabalho. Um trabalho que tem sentido, no geral é um trabalho em que se percebe o resultado. De acordo com Vieira (2005) só se consegue uma vida cheia de sentido fora do trabalho, se a vida no trabalho for dotada de sentido. Lamentavelmente um trabalho produzido por anos a fio de forma rotineira e sem as ferramentas adequadas, pode gerar processos de alienação e de descompensação psíquica. Analisando o discurso dos trabalhadores da FMD/UnB, percebe-se frustração e alienação em relação às tarefas, há indícios de que o trabalho vem perdendo o sentido e que a relação mantida com a organização é simplesmente presenteísta.

"Meu trabalho é bem rotineiro. Como a gente trabalha com aulas é aquela repetição todo dia, você expõe material para uma aula, retira depois, retira coloca outro. Não há excesso de trabalho."

(Entrevistado n. 1).

"Eu acredito que é a falta de estrutura da organização em termos de material, já que você empreende um serviço e fica faltando material para concluir". (Entrevistado n.8)

"O trabalho é minucioso e exige muito preparo, não pode haver erro (....). Atualmente trabalho sozinha e tenho cinco salas para tomar conta (...). Mas aguardo alguém para trabalhar comigo." (Entrevistado $n$. 11).

"Meu trabalho como técnico de laboratório é bastante complexo, trabalho tanto com a parte material, quanto humana, meu trabalho é conviver com os acertos e problemas que surgem. Dificuldades em desempenhar as tarefas existem, por termos aparelhos antigos e às vezes faltam reagentes, mas excesso de trabalho não há."

(Entrevistado n.3).

\section{3- Relações socioprofissionais}

Quanto às relações socioprofissionais que são caracterizadas pela dinâmica das interações entre os indivíduos, 01 dos entrevistados alegou uma 
relação distante com a chefia, os demais admitiram ter boa convivência com as chefias e colegas de trabalho e citaram o ambiente como sendo harmonioso, tranqüilo e de companheirismo, havendo troca inclusive de materiais $\mathrm{e}$ equipamentos. Essa confiabilidade, parceria e compatibilidade entre os trabalhadores são derivadas possivelmente da cultura e dos valores absorvidos da organização ao longo dos anos, e pode ser um aspecto favorável que beneficia a todos. Porém também pode ser observada do ponto de vista da Psicodinâmica do Trabalho, que indica como estratégias de mediação empregada pelos indivíduos para lidar com o trabalho e transformá-lo em fonte de prazer, a negação ou aceitação do sofrimento de forma individual ou coletiva, com fins de se adaptarem ou se manterem na Instituição. Ao analisar o discurso dos trabalhadores, é possível perceber que coletivamente, eles não só negam o sofrimento como o fazem de forma coletiva, tal estratégia pode estar sendo utilizada para adaptação e manutenção dentro do grupo.

"Me dou muito bem como meus e minha chefia, aqui não existe conflitos". (Entrevistado $n$ 1).

"Eu não tenho nenhum problema em questão de relacionamento, o professor com que eu trabalho é há quase trinta anos, eu me dou muito bem com ele, inclusive criei meus filhos aqui na UnB, foi meu único serviço até então. Eu acredito que esse é o melhor lugar pra se trabalhar..." (Entrevistado n.8).

\section{4- Danos físicos e psíquicos}

Os danos físicos e psíquicos decorrem dos fatores de risco a que são expostos os trabalhadores e que interferem diretamente no seu conforto durante a execução de suas tarefas e contribuem para o surgimento de doenças laborais a médio e longo prazo. Os técnicos de laboratório da UnB, mesmo quando expostos a riscos conseguem executar suas atividades, contudo, essa capacidade para solucionar problemas de maneira quase mágica em função da falta de recursos, gera conflitos entre o papel do indivíduo e o papel organizacional, ou seja os 
servidores assimilaram de tal forma a personalidade organizacional que tomam pra si as responsabilidades Institucionais.

Embora, 01 dos entrevistados tenha admitido que a exposição direta a reagentes químicos causava-lhe alergias e problemas respiratórios em momento nenhum ele acusou a Instituição de irresponsável, deixando implícito que o fato era inerente à sua atividade.

Os entrevistados cujo tempo de serviço era inferior a 10 anos expuseram sobre as suas dificuldades de adaptação a cultura imposta, mas para se manterem na Instituição "engoliram o choro" e juntaram-se ao grupo, percebendo que não havia possibilidades de mudanças. O que de fato é observável é que na UnB a cultura é extremamente arraigada, coibindo rupturas ou mudanças.

"De uma certa maneira às vezes afeta minha saúde, porque eu trabalho com algumas drogas e drogas são sempre irritantes, como exemplo o formol". (Entrevistado n. 1)

"Eu me sinto saudável, satisfeito e alegre por estar no meu trabalho." .(Entrevistado n.6)

\section{5- Percepção de sofrimento no trabalho}

Sofrimento no trabalho não tem uma manifestação única para todos os indivíduos. O que é sofrimento para um, não necessariamente é para o outro, é ainda um estado de expectativa diante do perigo (Brant e Minayo, 2004). Nesse estudo, 12 dos entrevistados disseram desconhecer o que é sofrimento e apenas 03 afirmaram ter vivido momentos de sofrimento. Dejours, Abdoucheli (1994 apud Barros e Mendes, 2003) consideram as estratégias defensivas, na sua maioria, coletivas. Esses autores definem as estratégias como mecanismos pelos quais o trabalhador busca modificar, transformar e minimizar a percepção da realidade que o faz sofrer. Os autores apontam que a diferença entre um mecanismo de defesa individual e um coletivo está no fato de que o primeiro permanece sem a presença física do objeto, que se encontra interiorizado. Ao passo que o segundo depende da presença de condições externas e se sustenta no consenso de um grupo específico de trabalhadores. Mendes (2007) afirma ainda, que as estratégias de defesa visam 
reduzir o custo humano e o sofrimento psíquico no trabalho por meio da utilização de mecanismos de negação e de controle excessivo, que protegem o ego, mas, podem conduzir à alienação quando utilizados excessivamente.

Quando indagados sobre: "Quais as principais causas de sofrimento no trabalho para você?" A maioria negou qualquer vivência de sofrimento, contudo, ao se alterar o questionamento para: "O que pode ser feito para minimizar o sofrimento vivenciado no seu trabalho?" Todos os servidores descreveram uma série de fatores, principalmente relacionados às condições de trabalho que thes forneciam vivências de sofrimento, havendo contradição no próprio discurso dos servidores.

"Os sentimentos são muito bons, porque eu me sinto muito bem fazendo o meu trabalho e fico realizado com o resultado."

(Entrevistado n. 2).

"Eu não tenho problema em relação ao meu trabalho, faço porque eu gosto" (Entrevistado n.8).

"Atualmente estou satisfeita com o meu trabalho, tenho sonhos, expectativas e trabalho para conquistar melhorias pessoais, profissionais e para a Instituição". (Entrevistado n.11).

"Eu gosto do meu trabalho e do que eu faço, o único problema é ganhar pouco". (Entrevistado n.14).

"Quem faz o que gosta se diverte". (Entrevistado n.12)

"Precisa de incentivo por parte da Instituição, atendimento das necessidades pessoais dos profissionais (....), condições de trabalho e valorização. (Entrevistado n.14)"

"A compra de mais equipamentos, pois os que tem são antigos e ineficientes." (Entrevistado n.8).

"Respeito por parte das chefias (professores) ao trabalho do técnico, redistribuição das tarefas, incluindo os novatos." (Entrevistado n.1).

"Tive que mudar minha maneira de ser por causa do sofrimento, meu comportamento era de alguém sem atitudes próprias, foram momentos 
difíceis, tive gastrite e depressão, por causa das atitudes do chefe, que gritava, exigia coisas e negava outras de direito". (Entrevistado n.11)

\section{5- Considerações Finais}

O contexto atual do trabalho é vivenciado diariamente por pressões, competitividade, busca por excelência e ainda, pela necessidade dos indivíduos de se perceberem como parte de uma sociedade e produzir para o seu desenvolvimento. Embora, a Instituição pesquisada seja uma organização pública, ela não se diferencia de empresas privadas, porque também necessita apresentar resultados, melhorar e expandir os serviços prestados em função inclusive de uma cobrança maior dos contribuintes.

"Eu gosto do meu trabalho e acho que não existe lugar melhor para se trabalhar". Essa fala foi muito ouvida durante as entrevistas, nela pode-se perceber que apesar de trabalhar em condições precárias, onde a infra-estrutura é inadequada, os equipamentos são obsoletos e falta até materiais básicos, como jaleco e luvas, os técnicos de laboratórios lotados na FMD/UnB, são trabalhadores que internalizaram a Instituição e não conseguem se desvincular. Um dado importante que ressalta essa idéia é o fato de que dois dos participantes já adquiriram há muito, o direito a aposentadoria, mas permanecem laborando diariamente, sem desejar se afastar dessa rotina.

O Regime Jurídico Único prevê a estabilidade para o servidor público, porém não é essa regulamentação que faz com que indivíduos permaneçam no mesmo ambiente por mais de 25 anos, já que para o funcionalismo as regras possibilitam transferências, redistribuição e remanejamentos internos externos sem prejuízo de benefícios e salários. Certamente a estabilidade também, não explica o orgulho demonstrado pelos participantes da pesquisa em fazer parte da Instituição, a crença de que ela é o melhor lugar para se trabalhar, mesmo sem condições adequadas, mesmo com baixos salários, tem sua origem no imaginário, na subjetivação coletiva, onde eles aprenderam a viver e conviver em harmonia com os problemas organizacionais. A relação entre os trabalhadores e a UnB, está 
estabelecida de forma muito intricada, explicitando o quanto eles internalizaram os valores e crenças da Instituição e o quanto não se reconhecem fora dela.

Todos os trabalhadores sem exceção alegaram estarem capacitados para execução de suas atividades e reforçaram isso com o discurso "já faço isso há mais de 20 anos", ressaltaram ainda, a questão dos equipamentos obsoletos, ou seja, é possível prever que quem faz uma atividade por mais de 20 anos utilizando os mesmos procedimentos, sem nenhuma mudança estrutural, não carece de treinamento e pode trabalhar sem que haja um controle e uma fiscalização muita rígida. Isso explica a razão da ausência de algumas chefias, como declarado por um dos participantes. Porém, também denota a falta de comprometimento da Instituição com o desenvolvimento dos profissionais, não havendo nessa relação nenhum incentivo ao crescimento, a busca por novas tecnologias e reconhecimento das habilidades e competências individuais ou dos grupos.

Quanto ao excesso de trabalho, os participantes foram unânimes ao admitir que não havia excesso e a maioria declarou exercer atividades rotineiras e contínuas, inerente a área de atuação dos indivíduos, onde existe a necessidade extrema de estabelecimento de prazos; execução seqüencial; cronologia e extrema atenção. No entanto, o trabalho rotineiro desenvolvido diariamente, ao longo do tempo pode se tornar um trabalho sem sentido e promover alienação que invariavelmente leva ao adoecimento psíquico.

Percebe-se que para a maioria a vivência no ambiente organizacional dos técnicos de laboratório é passível de relacionamentos estreitos e sem conflitos.

Apesar do resultado da pesquisa apresentar um sofrimento subjetivado coletivamente e que possivelmente não tenha implicado diretamente na produtividade e nem causado transtornos para a Instituição, as questões relacionadas às condições de trabalho são relevantes e, inevitavelmente causam prejuízos a saúde do trabalhador.

É clara a necessidade de melhoria na infra-estrutura dos laboratórios da Faculdade de Medicina e para tentar sanar o problema é necessário fazer análise ergonômica, proceder a troca dos equipamentos e a compra de materiais adequados com fins de corrigir a falha e promover a qualidade de vida no ambiente.

Há que se considerar também, que ao longo dos anos a UnB não trabalhou no sentido de desenvolver os recursos humanos da organização, não investiu em capacitação e tecnologia e promoveu a alienação coletiva dos técnicos 
de laboratório da FMD/UnB. Visualizando as relações de trabalho sob esse foco e sob a perspectiva da Psicodinâmica do Trabalho, há indícios de sofrimento para os trabalhadores, que deverão ser objetos de pesquisas com mais profundidade, com fins de investigação e uma possível intervenção. 
BARDIN, L. Análise de conteúdo. Lisboa: Ed.70, 1994.

BARROS \& MENDES, A.M. Sofrimento psíquico no trabalho e estratégias defensivas dos operários terceirizados da construção civil. Revista Psico-USF, v. 26, n. 2, p 55-64, Jul/Dez. 2001. Disponível em http://www.scielo.br. Acesso em: 12 fevereiro, 2008.

BRANT, L.C. \& MINAYO, G. A transformação do sofrimento em adoecimento: do nascimento da clínica à psicodinâmica do trabalho. Ciênc. Saúde coletiva, 2004, vol.9, n.01, p.213-223. Disponível em http://www.scielo.br. Acesso em 30 de maio, 2008.

DEJOURS, C. A banalização da injustiça social. $6^{a}$ ed. Rio de Janeiro: FGV, 2000.

DEJOURS, C. Da Psicopatologia à Psicodinâmica do Trabalho, Rio de janeiro: Editora Fiocruz Brasília: Paralelo 15. 2004 Disponível em: <http://www.scielo.br/pdf/csp/v21n3/39/>. Acesso em: 12 de fevereiro de 2008.

ENRIQUEZ, E. O homem do século XXI: sujeito autônomo ou indivíduo descartável. Université Paris VII, ERA-eletrônica, v.5, n.1, art.10, jan/jun. 2006. Disponível em <http://www.era.com.br/>. Acesso em: 12 de fevereiro de 2008.

FERREIRA, C.M \&MENDES, A. M. "Só de pensar em vir trabalhar, já fico de mau humor". Atividade de atendimento ao público e prazer-sofrimento, Estudos de Psicologia 2001, 6(1), 93-104.

FREITAS, M.E. Cultura organizacional: Identidade,sedução e carisma? Rio de Janeiro: FGV, 2000.

MENDES, A.M. Psicodinâmica do Trabalho: teoria,método e pesquisas. $1^{\text {a }}$ edição São Paulo . SP, 2007.

MENDES, A. M. e LINHARES, N. J. (1996). A prática do enfermeiro com pacientes da UTI: uma abordagem psicodinâmica. Revista Brasileira de Enfermagem, Brasília, 42 (2), 267-28.

MENDES, A. M. e ABRAHÃO, J. I. (1996). A Influência da organização do trabalho nas vivências de prazer-sofrimento dos trabalhadores: uma abordagem psicodinâmica. Revista: Psicologia Teoria e Pesquisa, 26 (2),179-184. 
SIQUEIRA, M.V.S. Gestão de pessoas e Discurso Organizacional. Goiânia: Ed. UCG, 2006.

VERGARA, S.C. Projetos e relatórios de pesquisa em administração. 8 ed. São Paulo: Atlas, 2004.

VIEIRA,A. P.(2005) Prazer,sofrimento e saúde no trabalho de teleatendimento. Dissertação de Mestrado, Universidade de Brasília,Brasília. 